\title{
Serum markers of GH and insulin action in 12-year-old children born small for gestational age
}

\author{
Sirpa Tenhola ${ }^{1}$, Pirjo Halonen ${ }^{2}$, Jarmo Jääskeläinen ${ }^{1}$ and Raimo Voutilainen ${ }^{1}$ \\ ${ }^{1}$ Department of Pediatrics, Kuopio University and University Hospital, PO Box 1777, FI-70211 Kuopio, Finland and ${ }^{2}$ IT Service Center, \\ Kuopio University, PO Box 1627, FI-70211 Kuopio, Finland
}

(Correspondence should be addressed to R Voutilainen; Email: raimo.voutilainen@uku.fi)

\begin{abstract}
Objectives: Our aim was to determine whether markers of growth hormone and insulin action differ between children born small for gestational age (SGA) and those born of an appropriate size for gestational age (AGA).

Design: Fifty-five SGA children and their 55 age- and sex-matched AGA control subjects were studied in a case-control setting at 12 years of age.

Methods: We examined serum concentrations of insulin-like growth factor (IGF)-I, IGF-II, IGF-binding protein (IGFBP)-1 and IGFBP-3, sex hormone binding globulin (SHBG), leptin, fasting insulin, and blood glucose. Insulin sensitivity was evaluated by the homeostasis model assessment for insulin resistance (HOMA-IR).

Results: The body mass index (BMI), sex, and puberty-adjusted mean serum IGF-I concentration was higher in the SGA than in the AGA children (303.4 vs $282.3 \mu \mathrm{g} / \mathrm{l}, P=0.006)$. The mean serum concentrations of IGF-II, IGFBP-I, IGFBP-3, SHBG, fasting insulin, blood glucose and HOMA-IR did not differ between the SGA and the AGA group. The BMI, sex, and puberty-adjusted mean serum leptin concentration was lower in the SGA than in the AGA children (7.9 vs 10.1 $\mu \mathrm{g} / \mathrm{l}$, $P=0.037)$. In multiple logistic regression analysis, high HOMA-IR predicted high serum IGF-I levels in the SGA children (odds ratio 8.3; 95\% confidence interval $1.7-41 ; P=0.010$ ), whereas in the AGA group HOMA-IR did not associate with the serum IGF-I level.

Conclusions: The BMI, sex, and puberty-adjusted mean serum IGF-I concentration was significantly higher and the leptin concentration was lower in the SGA than in the AGA children. No differences were found in the indices of insulin action or sensitivity between the SGA and AGA children at 12 years of age. However, HOMA-IR strongly associated with serum IGF-I levels in the SGA children.
\end{abstract}

European Journal of Endocrinology 152 335-340

\section{Introduction}

Low birth weight has been associated with type-2 diabetes, cardiovascular diseases and also with short stature in later life (1-4). Approximately $10 \%$ of children born small for gestational age (SGA) are short as adults (adult height $<-2$ s.D. scores) (3, 4). Furthermore, intrauterine growth restriction (IUGR) may influence the growth hormone $(\mathrm{GH})$ secretion profile in prepubertal children $(5-7)$.

The insulin-like growth factors (IGFs) mediate many of the anabolic and mitogenic actions of GH. Serum levels of IGF-I and IGF binding protein (IGFBP)-3 reflect the endogenous GH secretion in healthy children; short children have lower IGF-I and IGFBP-3 levels than taller ones (8). During fetal life serum IGF-I levels are relatively low increasing with gestational age (9). In newborns, serum IGF-I levels correlate with birth weight and length; the IGF-I concentrations are lower in SGA than in appropriate for gestational age (AGA) babies (9, 10). Serum IGF-I and IGFBP-3 concentrations increase slowly in early childhood with a steep increase during puberty, decreasing thereafter, while serum IGF-II concentrations are constant after the first few weeks of life $(11,12)$. Low birth weight has been associated with increased circulating concentrations of IGF-I in childhood (13-16). Cutfield and coworkers have reported that short IUGR born children have higher IGF-I and IGFBP-3 concentrations than their short AGA born control subjects at 7 to 8 years mean age (16). Furthermore, it has been hypothesized that abnormalities in somatotropic actions of $\mathrm{GH}$ and IGF-I in short SGA children may contribute directly to reduced insulin sensitivity (7). IGFBP-1 is a specific IGF binding protein acutely modulating IGF bioactivity. Its expression in hepatocytes is downregulated by insulin, and serum IGFBP-1 concentration is a sensitive marker of insulin action (17). IGFBP-1 serum levels decline with age in prepubertal children, and the lowest values are found in puberty (12). 
Leptin, produced by adipocytes, has a crucial role in the regulation of body fat mass, appetite and energy expenditure $(18,19)$. Leptin is detectable in fetal cord blood as early as 18 weeks of gestation, and at birth leptin concentration correlates with intrauterine growth $(20,21)$. In childhood, serum leptin levels increase with age, and girls tend to have higher levels than boys (22). In puberty, leptin levels decrease in boys, while the levels continue to increase in girls (22). In SGA children, leptin levels have been reported to be lower than in AGA children (23).

The aim of this study was to determine whether serum markers of GH (IGF-I, IGFBP-3) and insulin action (IGFBP-1, sex hormone binding globulin (SHBG)), insulin sensitivity (homeostasis model assessment for insulin resistance (HOMA-IR)), and leptin concentrations differ between SGA and AGA children in a population-based case-control setting.

\section{Subjects and methods}

\section{Definitions}

SGA was defined as birth weight or length or ponderal index $>2$ S.D. scores below the respective mean for the gestational age (24). The ponderal index was calculated as $\left[\right.$ weight $(\mathrm{g}) /$ length $\left.^{3}(\mathrm{~cm})\right] \times 100$. AGA was defined as birth weight, birth length and ponderal index $>-2$ s.D. scores and $<2$ S.D. scores of the respective mean for the gestational age. Full-term was applied to babies born at or after week 37 and before the 42 nd week of gestation (calculated from the beginning of the last menstruation). Body mass index (BMI) was defined according to the formula weight $(\mathrm{kg}) /$ height $^{2}(\mathrm{~m})$. HOMA-IR was calculated as [serum fasting insulin $(\mathrm{mU} / \mathrm{l}) \times$ blood glucose $(\mathrm{mmol} / \mathrm{l})] / 22.5$ (25).

\section{Subjects}

The study population consisted of all full-term children who were born SGA at Kuopio University Hospital, Finland, during a 22-month period between 1984 and 1986, 73 SGA children (70 singletons and three twins) were included in the study. Five 12-year-old children born SGA could not be reached, one child was excluded because of a metabolic disease, one child was excluded by age, and 11 were unwilling to participate in the study. Thus $18(24.7 \%)$ subjects of the original SGA children were excluded from the study. Each SGA child had, as the control subject, the next born full-term AGA child matched for sex. At the age of 12 years, 55 SGA children ( 20 boys and 35 girls) and 55 AGA control subjects participated in this study. The mean age in both the study and the control group was 12.2 (S.D. 0.2) years. The study protocol was approved by the Research Ethics Committee of Kuopio University Hospital. Informed written consent was obtained from the child and the parents.

\section{Methods}

Perinatal data Perinatal data were obtained from hospital records. The birth measures were converted to S.D. scores by plotting them on the growth charts and adjusting the birth measures for duration of gestation and for gender (24). The mean birth weights and lengths for the SGA and AGA groups were $2452 \mathrm{~g}$ $(-2.44$ S.D. score) vs $3455 \mathrm{~g}(-0.24$ S.D. score), $P<0.001$, and $46.2 \mathrm{~cm}(-2.27$ S.D. score $)$ vs $50.4 \mathrm{~cm}(-0.08$ S.D. score), $P<0.001$ respectively. A detailed description of the perinatal characteristics has been reported previously (26). The mean birth measures of the children who dropped out of the study did not differ from those of the participating SGA children.

Anthropometric measures and pubertal development Height was measured in the 12-year-old children with a calibrated Harpenden stadiometer (Holtain Ltd, Crymych, Dyfed, UK) and recorded to the nearest $0.1 \mathrm{~cm}$, and weight was recorded to the nearest $0.1 \mathrm{~kg}$. Height was converted to S.D. scores and weight to percentages in relation to the mean weight-forheight by using the current Finnish reference values for height and weight-for-height (Pegasos V 3.9.2, Pediatric Research Foundation, Helsinki, Finland). A complete physical examination was performed on all children. The anthropometric measures at the age of 12 years in the SGA and AGA children are presented in Table 1. Pubertal development was assessed according to the Tanner staging scale $(27,28)$. For the statistical analyses, pubertal stage was defined by breast scores for girls and genital scores for boys (scores 1-5). Pubertal development did not differ between the SGA and AGA children at 12 years of age $(P=0.917$, the marginal homogeneity test), even when the sexes were analyzed separately.

Laboratory methods Blood samples were taken in the morning, between $0900 \mathrm{~h}$ and $1000 \mathrm{~h}$, after an overnight fast. An intravenous cannula was placed in the antecubital vein for blood sampling, and blood samples were drawn through the cannula. Serum IGF-I and

Table 1 Anthropometric data of the children born SGA and AGA at the age of 12 years. A more detailed description of the anthropometric data is described in a previous paper (26). Values are shown as the mean (S.D.).

\begin{tabular}{lcc}
\hline Variable & SGA $(n=55)$ & AGA $(n=55)$ \\
\hline Height (s.D. score) & $-0.16(0.90)^{\star \star \star}$ & $+0.60(1.00)$ \\
Height (cm) & $150.1(6.7)^{\star \star \star}$ & $155.8(7.5)$ \\
Weight for height (\%) & $-1(17)^{\star}$ & $+9(22)$ \\
Weight $(\mathrm{kg})$ & $39.7(7.6)^{\star \star \star}$ & $48.6(13.2)$ \\
Body mass index $\left(\mathrm{kg} / \mathrm{m}^{2}\right)$ & $17.5(2.9)^{\star \star}$ & $19.8(4.2)$ \\
\hline
\end{tabular}

${ }^{* * *} P<0.001,{ }^{* *} P<0.01,{ }^{*} P<0.05$, SGA vs AGA (Wilcoxon matchedpairs signed rank test for differences). 
IGF-II concentrations were analyzed by ELISA (DSL-105600 ACTIVE IGF-I ELISA; DSL-10-9100 ACTIVE IGFII ELISA, both from Diagnostic Systems Laboratories, Inc., Webster, TX, USA). The assays include an extraction step in which IGFs are separated from their binding proteins in serum. The intra-assay coefficient of variation $(\mathrm{CV})$ for IGF-I was $6.5 \%$, and the interassay CV was $6.4 \%$, as reported by the manufacturer; for IGF-II the respective coefficients of variation were $3.5 \%$ and $5.2 \%$. Serum IGFBP-1 and IGFBP-3 concentrations were analyzed by ELISA (DSL-10-7800 ACTIVE Total IGFBP-1 ELISA; DSL-10-6600 ACTIVE IGFBP-3 ELISA, both from Diagnostic Systems Laboratories). The intra- and interassay coefficients of variation for IGFBP-1 were $2.5 \%$ and $6.8 \%$, and for IGFBP-3 $7.3 \%$ and $8.2 \%$ respectively. Serum leptin concentrations were analyzed by ELISA (Quantikine DLP00, R\&D Systems, Inc., Minneapolis, MN, USA). The intra- and interassay coefficients of variation were $3.2 \%$ and $3.5 \%$ respectively. Serum SHBG was measured by the AutoDELFIA SHBG time-resolved fluoroimmunoassay (TR-FIA) method (Perkin Elmer Life Sciences Wallac, Turku, Finland). The intra- and interassay coefficients of variation were $4.0 \%$ and $2.6 \%$ respectively. Serum insulin concentrations were determined by RIA (Phadeseph Insulin RIA, Pharmacia \& Upjohn Diagnostics AB, Uppsala, Sweden) The intra- and interassay coefficients of variation for insulin were $5.3 \%$ and $7.6 \%$ respectively. Blood glucose concentrations were analyzed by a glucose oxidase method (Enzyme Electrode, Nova Biomedical, Waltham, MA, USA), and the respective coefficients of variation were $3 \%$ and $5 \%$.

\section{Data analyses}

Data were analyzed using the statistical program SPSS for Windows, release 10.0 (SPSS Inc., Chicago, IL, USA). All continuous variables were examined for normality with the Kolmogorov-Smirnov test. Non-normally distributed variables were log transformed before testing with parametric tests. Correlation coefficients were examined by Pearson's or Spearman's correlation tests. The Wilcoxon matched pairs signed rank test or paired sample $t$-test was used in comparing the means between the SGA and AGA group. Due to the skew distribution of serum leptin concentrations, median and range were reported in addition to the mean and S.D.. In comparing the differences between the sexes, the Mann-Whitney test was used. Serum markers of $\mathrm{GH}$ and insulin action were analyzed by paired sample $t$-test and repeated measures ANOVA adjusting for sex, difference of BMI, and puberty among the SGA-AGA pairs. Pubertal discrepancy was coded as -1 , 0 or 1 , when the SGA child had a lower, equal or higher score of pubertal development than the AGA control subject. Thus, discrepancy in pubertal development was included in the models as two dummy variables. If the repeated measures ANOVA gave a statistically significant result, double data of these comparisons were presented (Table 2). The factors associating with serum IGF-I level were studied by the multiple logistic regression analysis. A significance level of $P<0.05$ was used for all analyses.

\section{Results}

\section{Serum markers of GH action}

Due to the differences in current weight, height and BMI between the SGA and AGA groups, the IGF-I concentrations were analyzed by adjusting for BMI, sex, and puberty. After adjusting for these variables, the mean serum IGF-I concentration was significantly higher in the SGA than in the AGA children (Table 2). Furthermore, IGF-I concentrations were higher in both the SGA and AGA girls, when compared with their

Table 2 The means (S.D.) of serum (S) IGF-I, IGF-II, IGFBP-1, IGFBP-3, fasting insulin, SHBG, leptin (the median and range) and blood (B) glucose concentrations and HOMA-IR at 12 years of age in the children born SGA and AGA.

\begin{tabular}{|c|c|c|c|}
\hline Variable & SGA $(n=55)$ & $\mathbf{A G A}(n=55)$ & $P$-value ${ }^{a}$ \\
\hline S-IGF-I $(\mu \mathrm{g} / \mathrm{l})$ & $327.2(126.2)$ & $310.1(127.6)$ & 0.300 \\
\hline Girls & $373.7(118.3)^{b}$ & $351.5(112.9)^{b}$ & 0.508 \\
\hline Boys & $245.8(96.1)$ & $237.5(121.6)$ & 0.398 \\
\hline S-IGF-I $(\mu \mathrm{g} / \mathrm{l})^{\mathrm{C}}$ & 303.4 & 282.3 & $0.006^{c}$ \\
\hline S-IGF-II $(\mu \mathrm{g} / \mathrm{l})$ & $849.3(117.0)$ & $835.3(112.4)$ & 0.535 \\
\hline S-IGFBP-3 $(\mu \mathrm{g} / \mathrm{I})$ & 4763.5 (1566.0) & 4269.3 (1368.8) & 0.124 \\
\hline S-Insulin (mU/l) & $9.8(3.5)$ & $10.6(5.1)$ & 0.617 \\
\hline B-Glucose (mmol/l) & $4.4(0.3)$ & $4.3(0.3)$ & 0.558 \\
\hline HOMA-IR & $1.91(0.74)$ & $2.03(0.96)$ & 0.694 \\
\hline S-IGFBP-1 ( $\mu \mathrm{g} / \mathrm{l})$ & $70.0(34.8)$ & $58.8(30.3)$ & 0.090 \\
\hline S-SHBG (nmol/l) & 76.4 (30.3) & 72.4 (35.9) & 0.564 \\
\hline S-Leptin $(\mu \mathrm{g} / \mathrm{l})$ & $12.7(11.8)$ & $18.7(20.4)$ & 0.233 \\
\hline & $9.0(0.8-50.7)^{d}$ & $9.4(0.9-101.5)^{d}$ & \\
\hline S-Leptin $(\mu \mathrm{g} / \mathrm{l})^{\mathrm{c}}$ & 7.9 & 10.1 & $0.037^{\mathrm{C}}$ \\
\hline
\end{tabular}

${ }^{\text {a } P a i r e d ~ s a m p l e ~} t$-test for differences; ${ }^{b}$ Mann-Whitney test between the sexes, $P \leq 0.001$; ${ }^{c}$ repeated measures ANOVA adjusted for BMI, sex, and puberty; estimated marginal means are presented; ${ }^{d}$ median (range). 
male peers. The means of IGF-II and IGFBP-3 concentrations did not differ between the SGA and AGA children (Table 2).

\section{Serum markers of insulin action and leptin concentrations}

The means of serum insulin and blood glucose concentrations and HOMA-IR did not differ between the SGA and AGA children, even after BMI, sex, and puberty were adjusted. Neither did the means of serum IGFBP-1 and SHBG concentrations differ between the SGA and AGA groups. After adjusting for BMI, sex, and pubertal development, the mean leptin concentration was lower in the SGA than in the AGA children (Table 2). In both the SGA and AGA group, HOMA-IR correlated positively with IGF-I (respectively $r=0.525, P<0.001$ and $r=0.438, P=0.001$ ), and with leptin levels (respectively $r=0.384, \quad P=0.004$ and $r=0.650, \quad P<$ $0.001)$, while serum IGFBP-1 correlated inversely with IGF-I (respectively $r=-0.285, P=0.035$ and $r=$ $-0.436, \quad P=0.001$ ), HOMA-IR (respectively $r=-0.496, P<0.001$ and $r=-0.718, P<0.001$ ) and leptin levels (respectively $r=-0.460, P<0.001$ and $r=-0.609, \quad P<0.001)$. HOMA-IR did not correlate with serum IGF-II concentrations.

\section{Factors associated with high IGF-I levels in the SGA and AGA children}

In the multiple logistic regression analyses, the IGF-I variable was dichotomized in the SGA and AGA groups; as the cut-off point we used the IGF-I level of the 75 th percentile of the AGA group $(408.9 \mu \mathrm{g} / \mathrm{l})$. Sixteen (29.1\%) SGA children passed this limit. According to the multiple logistic regression analysis, HOMAIR associated strongly with a high serum IGF-I level in the SGA children. An increase of 1.0 unit in HOMA-IR increased by 8.3 -fold the risk of a high serum IGF-I level. The other covariates in the model did not reach statistical significance (Table 3). Similar analyses were performed in the AGA children; none of the covariates reached statistical significance (data not shown). The SGA children in the highest IGF-I quartile of the AGA group $(n=16)$ had significantly higher BMI $(P=0.021)$, weight $(P=0.038)$ and weight-forheight $(P=0.040)$, and they tended to have lower birth weight $(P=0.077)$ than the SGA children in the lower IGF-I quartiles $(n=39)$. Current height, expressed in S.D. scores, did not differ between these SGA subgroups $(P=0.846)$.

\section{Discussion}

We found that the BMI, sex, and puberty-adjusted mean serum IGF-I concentration was significantly higher, and the leptin concentration significantly lower in the 12-year-old SGA children than in their age- and sex-matched AGA control subjects. In the SGA children HOMA-IR associated with high circulating IGF-I levels in multiple logistic regression analysis.

The strengths of this study are its population-based sample and the case-control setting, in which the SGA children were matched by age and sex with their AGA control children. Although pubertal development did not differ between the SGA and AGA groups, we aimed to eliminate possible differences of pubertal development between the SGA-AGA pairs by adjusting it in the analyses. Furthermore, due to the significant differences in current weight, height, and BMI between the SGA and AGA children, we adjusted BMI in the analyses.

Serum IGF-I levels are age and puberty related (11, 29). In addition, current body composition and early catch-up growth may influence the circulating IGF-I concentration $(14,15)$. Ong and co-workers reported that IGF-I levels at 5 years of age are positively related to current weight and height, and to catch-up growth in weight or height between 0 and 2 years (15). Garnett and co-workers found that IGF-I levels in 7- to 8-year-old prepubertal children are inversely related to birth size, but positively related to current weight; consequently those who were smaller at birth but heavier at 7-8 years had the highest IGF-I levels (14). In our study, the circulating serum IGF-I concentrations were significantly higher in the SGA children than in their matched control subjects, when puberty, sex, and BMI were adjusted in the analysis. This finding is consistent with the recent reports showing that low birth weight has an inverse relationship with serum IGF-I levels (13-16). On the other hand, Woods et al. did not find any difference in IGF-I levels between prepubertal short SGA and short AGA children (7).

Table 3 Factors associating with high serum IGF-I concentration (the highest IGF-I quartile) in the SGA children ( $n=55$ ). Multiple logistic regression analysis.

\begin{tabular}{lcccc}
\hline Variables $^{1}$ & Regression coefficient & Significance & Odds ratio (OR) & Confidence interval for OR (95\%) \\
\hline HOMA-IR & 2.12 & 0.010 & 8.3 & $1.7-41$ \\
Low birth weight (unit $100 \mathrm{~g})$ & 0.25 & 0.142 & 1.3 & $0.9-1.8$ \\
High BMl (kg/m ${ }^{2}$ ) & 0.18 & 0.255 & 1.2 & $0.9-1.6$ \\
Female sex & 1.61 & 0.172 & 5.0 & $0.5-50$ \\
\hline
\end{tabular}

${ }^{1}$ Adjusted for pubertal stage.

Variation explained by the model: $57.0 \%$. 
However, in that study the SGA children were significantly shorter and leaner than their control subjects, and the comparison was not adjusted by current size. Furthermore, Cutfield et al. reported that IUGR children had higher IGF-I levels than short normal children, but lower levels than children with normal weight and height (16). In the present study, the SGA and AGA girls had significantly higher IGF-I concentrations than their male peers. A similar sex difference in prepubertal children has been reported previously $(13,14)$. In addition, girls reach their maximal IGF-I level earlier than boys - on average at 14.5 years of age and boys one year later (11).

Abnormalities in insulin sensitivity and glucose metabolism have been detected in childhood and early adulthood in individuals born SGA $(7,30-32)$. Recently, a hyperinsulinemic euglycemic clamp study revealed reduced insulin sensitivity in prepubertal SGA children (30). An intravenous glucose tolerance test showed higher early insulin response and lower insulin sensitivity in prepubertal short IUGR children than in short control children (31). Furthermore, higher fasting insulin levels, lower insulin sensitivity, and lower IGFBP-1 levels were found in 2- to 8-yearold SGA children when compared with normal birth weight controls (7). On the contrary, we found no differences in the means of fasting insulin, glucose or HOMA-IR between the SGA and AGA children, even though BMI, sex, and puberty were adjusted in the analyses. Possibly, fasting insulin levels and HOMA indices, the methods we used, were not sensitive enough to find differences between the groups. In addition, the SGA populations in different studies are not comparable; our sample was population-based, while some are selected to consist of short SGA children only. In the present study, neither the serum IGFBP-1 nor the SHBG levels, which have been suggested to be useful markers of insulin sensitivity (33), indicated decreased insulin sensitivity in the SGA children. HOMA-IR and fasting insulin levels correlated positively with IGF-I and inversely with serum IGFBP-1 concentrations in the SGA and AGA children. Moreover, in logistic regression analysis HOMA-IR was a significant factor associating with high circulating IGF-I levels in the SGA, but not in the AGA, group. The SGA children with higher current BMI and lower birth weight tended to be less insulin sensitive and to have higher IGF-I levels. In accordance with our findings, Cutfield et al. found a positive correlation between fasting insulin and IGF-I levels (16). On the other hand, in an adult study population high circulating concentrations of IGF-I were associated with a reduced risk for developing impaired glucose tolerance and type-2 diabetes (34). It has been suggested that IGF-I might have GH-independent effects on insulin sensitivity, and circulating IGF-I levels could have an important role in the regulation of insulin sensitivity and maintenance of insulin secretion (35).
We found that the BMI, sex, and puberty-adjusted serum leptin concentration was lower in the SGA than in the AGA group. This agrees with previous studies on leptin levels in SGA children. Woods et al. reported that short prepubertal SGA children have lower leptin levels than their short control children with normal birth weight (7). According to Boguzewski et al., SGA children, with an age range of 2.0 to 12.8 years, had lower leptin levels than AGA children of the same age range (23).

In conclusion, the BMI, sex, and puberty-adjusted mean serum IGF-I concentration was significantly higher in the SGA than in the AGA children, which possibly reflects intrauterine programming of the GHIGF-I axis and/or relative IGF-I resistance in SGA children. No differences were found in the indices of insulin action or sensitivity between the SGA and AGA children at 12 years of age. However, HOMA-IR strongly associated with serum IGF-I levels in the SGA children.

\section{Acknowledgements}

This study was supported by Kuopio University Hospital, the Emil Aaltonen Foundation, the Finnish Cultural Foundation, the Maud Kuistila Foundation, the Sigrid Juselius Foundation, and the Academy of Finland.

\section{References}

1 Hales CN, Barker DJ, Clark PM, Cox LJ, Fall C, Osmond C \& Winter PD. Fetal and infant growth and impaired glucose intolerance at age 64. British Medical Journal 1991303 1019-1022.

2 Barker DJP, Gluckman PD, Godfrey KM, Harding JE, Owens JA \& Robinson JS. Fetal nutrition and cardiovascular disease in adult life. Lancet 1993341 938-941.

3 Karlberg J \& Albertsson-Wikland K. Growth in full-term small-forgestational-age infants: from birth to final height. Pediatric Research $199538733-739$.

4 Albertsson-Wikland K, Boguszewski M \& Karlberg J. Children born small-for-gestational age: postnatal growth and hormonal status. Hormone Research 199849 (Suppl 2) 7-13.

5 de Waal WJ, Hokken-Koelega AC, Stijnen T, de Muinck KeizerSchrama SM \& Drop SL. Endogenous and stimulated GH secretion, urinary GH excretion, and plasma IGF-I and IGF-II levels in prepubertal children with short stature after intrauterine growth retardation. The Dutch Working Group on Growth Hormone. Clinical Endocrinology $199441621-630$.

6 Boguszewski M, Rosberg S \& Albertsson-Wikland K. Spontaneous 24-hour growth hormone profiles in prepubertal small for gestational age children. Journal of Clinical Endocrinology and Metabolism $1995 \mathbf{8 0} 2599-2606$.

7 Woods KA, Helvoirt M, Ong KKL, Mohn A, Levy J, de Zegher F \& Dunger DB. The somatotropic axis in short children born small for gestational age: relation to insulin resistance. Pediatric Research $2002 \mathbf{5 1} 76-80$.

8 Blum WF, Albertsson-Wikland K, Rosberg S \& Ranke MB. Serum levels of insulin-like growth factor I (IGF-I) and IGF binding protein 3 reflect spontaneous growth hormone secretion. Journal of Clinical Endocrinology and Metabolism 199376 1610-1616.

9 Leger J, Oury JF, Noel M, Baron S, Benali K, Blot P \& Czernichow P. Growth factors and intrauterine growth retardation. I. Serum growth hormone, insulin-like growth factor (IGF)-I, IGF-II, and IGF binding protein 3 levels in normally grown and growth 
retarded human fetuses during the second half of gestation. Pediatric Research 199640 94-100.

10 Ogilvy-Stuart AL, Hands SJ, Adcock CJ, Holly JM, Matthews DR, Mohamed-Ali V, Yudkin JS, Wilkinson AR \& Dunger DB. Insulin, insulin-like growth factor I (IGF-I), IGF-binding protein-1, growth hormone, and feeding in the newborn. Journal of Clinical Endocrinology and Metabolism 199883 3550-3557.

11 Juul A, Bang P, Hertel NT, Main K, Dalgaard P, Jørgensen K, Müller J. Hall K \& Skakkebæk NE. Serum insulin-like growth factor-I in 1030 healthy children, adolescents, and adults: relation to age, sex, stage of puberty, testicular size, and body mass index. Journal of Clinical Endocrinology and Metabolism $199478744-752$.

12 Juul A, Dalgaard P, Blum WF, Bang P, Hall K, Michaelsen KF, Müller J \& Skakkebæk NE. Serum levels of insulin-like growth factor (IGF)-binding protein-3 (IGFBP-3) in healthy infants, children and adolescents: the relation to IGF-I, IGF-II, IGFBP-1, IGFBP-2, age, sex, body mass index, and pubertal maturation. Journal of Clinical Endocrinology and Metabolism $1995 \mathbf{8 0}$ $2534-2542$.

13 Fall CHD, Pandit AN, Law CM, Yajnik CS, Clark PM, Breier B, Osmond C, Shiell AW, Gluckman PD \& Barker DJP. Size at birth and plasma insulin-like growth factor-I concentrations. Archives of Diseases in Childhood 199573 287-293.

14 Garnett S, Cowell CT, Bradford D, Lee J, Tao C, Petrauskas V, Fay R \& Baur LA. Effects of gender, body composition and birth size on IGF-I in 7- and 8-year-old children. Hormone Research 199952 221-229.

15 Ong K, Kratzsch J. Kiess W, Dunger D \& The Alspac Study Team, Circulating IGF-I levels in childhood are related to both current body composition and early postnatal growth rate. Journal of Clinical Endocrinology and Metabolism 200287 1041-1044.

16 Cutfield WS, Hofman PL, Vickers M, Breier B, Blum WF \& Robinson EM. IGFs and binding proteins in short children with intrauterine growth retardation. Journal of Clinical Endocrinology and Metabolism 200287 235-239.

17 Suikkari AM, Koivisto VA, Rutanen EM, Yki-Järvinen $\mathrm{H}$ Karonen SL \& Seppälä M. Insulin regulates the serum levels of low molecular weight insulin-like growth factor-binding protein. Journal of Clinical Endocrinology and Metabolism $1988 \mathbf{6 6}$ $266-272$.

18 Considine RV, Sinha MK, Heiman ML, Kriauciunas A, Stephens TW, Nyce MR, Ohannesian JP, Marco CC, McKee LJ, Bauer TL \& Caro JF. Serum immunoreactive-leptin concentrations in normal-weight and obese humans. New England Journal of Medicine $1996334292-295$.

19 Reseland JE, Anderssen SA, Solvoll K, Hjermann I, Urdal P, Holme I \& Drevon CA. Effect of long-term changes in diet and exercise on plasma leptin concentrations. American Journal of Clinical Nutrition 200173 240-245.

20 Jaquet D, Leger J, Levy-Marchal C, Oury JF \& Czernichow P. Ontogeny of leptin in human fetuses and newborns: effect of intrauterine growth retardation on serum leptin concentrations. Journal of Clinical Endocrinology and Metabolism $1998 \mathbf{8 3}$ $1243-1246$

21 Koistinen HA, Koivisto VA, Andersson S, Karonen SL, Kontula K, Oksanen L \& Teramo KA. Leptin concentration in cord blood correlates with intrauterine growth. Journal of Clinical Endocrinology and Metabolism 199782 3328-3330.

22 Blum WF, Englaro P, Hanitsch S, Juul A, Hertel NT, Müller J, Skakkebæk NE, Heiman ML, Birkett M, Attanasio AM, Kiess W
\& Rascher W. Plasma leptin levels in healthy children and adolescents: dependence on body mass index, body fat mass, gender, pubertal stage, and testosterone. Journal of Clinical Endocrinology and Metabolism 199782 2901-2910.

23 Boguszewski M, Dahlgren J, Bjarnason R, Rosberg S, Carlsson LMS, Carlsson B \& Albertsson-Wikland K. Serum leptin in short children born small for gestational age: relationship with the growth response to growth hormone treatment. European Journal of Endocrinology 1997137 387-395.

24 Pihkala J, Hakala T, Voutilainen P \& Raivio K. New Finnish fetal growth charts (in Finnish). Duodecim 1989105 1540-1546.

25 Uwaifo GI, Fallon EM, Chin J, Elberg J, Parikh SJ \& Yanovski JA. Indices of insulin action, disposal, and secretion derived from fasting samples and clamps in normal glucose-tolerant black and white children. Diabetes Care 200225 2081-2087.

26 Tenhola S, Martikainen A, Rahiala E, Herrgård E, Halonen P \& Voutilainen R. Serum lipid concentrations and growth characteristics in 12-year-old children born small for gestational age. Pediatric Research 200048 623-628.

27 Marshall WA \& Tanner JM. Variations in pattern of pubertal changes in girls. Archives of Diseases in Childhood $1969 \mathbf{4 4}$ 291-294

28 Marshall WA \& Tanner JM. Variations in pattern of pubertal changes in boys. Archives of Diseases in Childhood 197045 $13-16$.

29 Löfqvist C, Andersson E, Gelander L, Rosberg S, Blum WF \& Albertsson-Wikland K. Reference values for IGF-I throughout childhood and adolescence: a model that accounts simultaneously for the effect of gender, age, and puberty. Journal of Clinical Endocrinology and Metabolism 200186 5870-5876.

30 Veening MA, van Weissenbruch MM \& Delemarre-van de Waal HA. Glucose tolerance, insulin sensitivity, and insulin secretion in children born small for gestational age. Journal of Clinical Endocrinology and Metabolism 200287 4657-4661.

31 Hofman PL, Cutfield WS, Robinson EM, Bergman RN, Menon RK, Sperling MA \& Gluckman PD. Insulin resistance in short children with intrauterine growth retardation. Journal of Clinical Endocrinology and Metabolism 199782 402-406.

32 Jaquet D, Gaboriau A, Czernichow P \& Levy-Marchal C. Insulin resistance early in adulthood in subjects born with intrauterine growth retardation. Journal of Clinical Endocrinology and Metabolism 200085 1401-1406.

33 Yki-Järvinen H, Mäkimattila S, Utriainen T \& Rutanen EM. Portal insulin concentrations rather than insulin sensitivity regulate serum sex hormone-binding globulin and insulin-like growth factor binding protein 1 in vivo. Journal of Clinical Endocrinology and Metabolism $1995803227-3232$.

34 Sandhu MS, Heald AH, Gibson JM, Cruickshank JK, Dunger DB \& Wareham NJ. Circulating concentrations of insulin-like growth factor-I and development of glucose intolerance: a prospective observational study. Lancet 2002359 1740-1745.

35 Dunger DB, Ong KKL \& Sandhu MS. Serum insulin-like growth factor-I levels and potential risk of type 2 diabetes. Hormone Research 200360 (Suppl 3) 131-135.

Received 21 September 2004

Accepted 14 December 2004 